\title{
ARE SOME LIFE-HISTORY STRATEGIES MORE VULNERABLE TO THE GENETIC CONSEQUENCES OF HABITAT FRAGMENTATION? A CASE STUDY USING SOUTH AUSTRALIAN CALADENIA R. BR. (ORCHIDACEAE) SPECIES
}

\author{
Lachlan W. Farrington ${ }^{1,2,4}$, Jose M. Facelli', Stephen C. Donnellan ${ }^{2,3}$ \\ \& ANDY D. Austin ${ }^{1,2}$ \\ ${ }^{1}$ School of Earth and Environmental Sciences, The University of Adelaide, SA 5005, Australia. \\ ${ }^{2}$ Australian Centre for Evolutionary Biology and Biodiversity, The University of Adelaide, SA 5005, Australia. \\ ${ }^{3}$ Evolutionary Biology Unit, South Australian Museum, North Terrace, Adelaide, SA 5000, Australia. \\ ${ }^{4}$ Author for corresondence: Lachlan.Farrington@adeleaide.edu.au
}

KEY WoRDS: habitat fragmentation, life history, population genetics, Caladenia, pollination, South Australia

Habitat fragmentation, through land clearing, has been attributed in the demise of many species of plants and animals throughout the world (Kinzig and Harte 2000). Not surprisingly, much research effort has been devoted toward understanding the dynamics of populations subject to fragmentation.

The Mount Lofty Ranges, adjacent to the South Australian capital city of Adelaide, constitute a region where fragmentation, through land clearing, has been prevalent (Paton 2000). The area was historically home to a number of endemic orchid species which are now either extinct or under threat (Barker et al. 2005). The contemporary distribution of species that are still present, particularly of the genus Caladenia $\mathrm{R}$. Br. (Orchidaceae), is interesting with respect to a diversity of traits in habitat requirements and pollination specificity. Some of these species are quite prolific while others are only found in remnant patches and it is not clear what is driving these differences. It is generally considered that habitat reduction effects plant population dynamics on several fronts by reducing recruitment potential through loss of pollinating agents (Aguilar et al. 2006), restricting potential for range expansion (Opdam \& Wascher 2004) and interrupting natural disturbance regimes (Coates et al. 2006). However, the interactions driving these responses are often complex and management regimes require a thorough understanding of key processes if they are to be successful. In order to evaluate the effects of these variables, this study
TABle 1. Pollination specificities (Cingel 2001) for three species of Caladenia found in the Mount Lofty region of South Australia.

Pollination Specificity

\begin{tabular}{l|l}
\hline High & Caladenia tentaculata \\
\hline Moderate & Caladenia rigida \\
\hline Low & Caladenia carnea var. carnea \\
\hline
\end{tabular}

adopts the conservation genetics paradigm (Ouborg et al. 2006) as a means of identifying species and populations that have been effected by fragmentation and aims to associate the level of impact with life history characteristics.

The presenter discussed the results from an investigation of microsatellite allelic diversity and structure among populations of three species expressing a range of pollination specificities (table 1).

ACKNOWLEDGEMENTS. This project is funded through the Australian Research Council with support from South Australian Museum, Department for Environment and Heritage South Australia, Earth Sanctuaries Foundation of Australia Inc. and Royal Zoological Society of South Australia Inc.

\section{LiterATURE CITED}

Aguilar, R., L. Ashworth, L. Galetto \& M.A. Aizen. 2006. Plant reproductive susceptibility to habitat fragmentation: review and synthesis through a meta-analysis. Ecology Letters 9: 968-980. 
Barker, W.R., R.M. Barker, J.P. Jessop, \& H.P. Vonow. 2005. Census of South Australian Vascular Plants. $5^{\text {th }}$ Edition. Journal of the Adelaide Botanic. Gardens. Supplement 1 (Botanic Gardens of Adelaide and State Herbarium: Adelaide).

Cingel van der, N.A. 2001. An Atlas of orchid pollination : America, Africa, Asia and Australia. Rotterdam, A.A. Balkema. 296 p.

Coates, F., I.D. Lunt \& R.L. Tremblay. 2006. Effects of disturbance on population dynamics of the threatened orchid Prsophyllum correctum D.L. Jones and implications for grassland management in south-eastern Australia. Biol. Conserv. 129: 56-69.
Kinzig, A.P., \& J. Harte. 2000. Implications of endemics-area relationships for estimates of species extinctions. Ecology 81(12): 3305-3311.

Opdam, P. \& D. Wascher. 2004. Climate change meets habitat fragmentation: linking landscape and biogeographical scale levels in research and conservation. Biol. Conserv. 117(3): 285-297.

Ouborg, N.J., P. Vergeer \& C. Mix. 2006. The rough edges of the conservation genetics paradigm for plants. J. Ecol. 94: 1233-1248.

Paton, D.C. 2000. Disruption of bird-plant pollination systems in southern Australia. Conserv. Biol. 14: 12321234.

Lachlan Farrington's research interests are in the application of genetic techniques to the management and conservation of natural systems. He is currently employed as a Research Associate at the University of Adelaide undertaking a study of genetic variation in orchid species found in and around the Mount Lofty Ranges near Adelaide.

José Facelli is an Associate Professor at the University of Adelaide's Environmental Biology department. His interests lie in terrestrial plant ecology, particularly the role of spatial and temporal heterogeneity in the structure and function of ecological systems. Recently, he has initiated several projects studying the impact of fragmented habitats on the genetic diversity and population dynamics of orchids.

Stephen Donnellan uses molecular genetic technologies to investigate issues in natural resource management, conservation biology, biodiversity and systematics. Most of his research has focused on vertebrates from the Australo-papuan region.

Professor Andy Austin is the Director of the the Australian Centre for Evolutionary Biology \& Biodiversity at The University of Adelaide. His research interests include the systematics and evolution of parasitic wasps, the biology of spiders, phylogeography of short-range edemic species, and the conservation biology of terrestrial and freshwater invertebrates. 